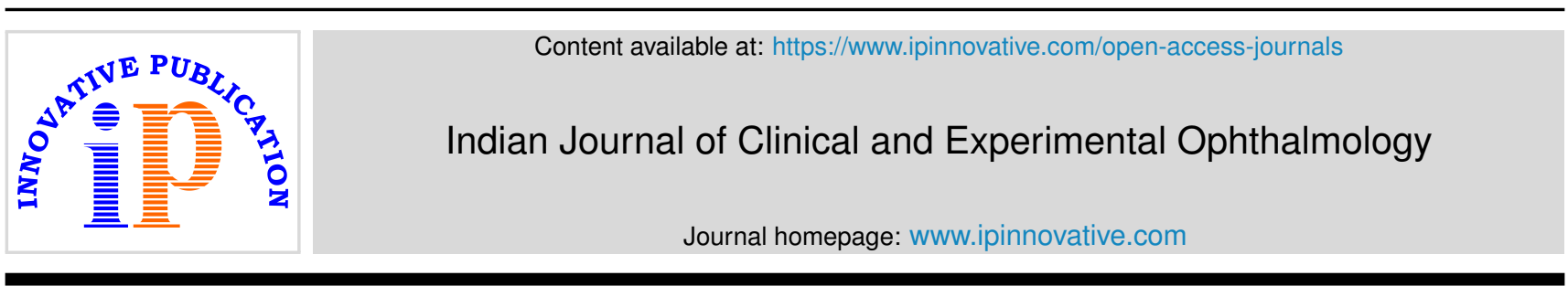

\title{
Editorial
}

\section{COVID-19 and Ophthalmologists}

\author{
Rajendra P Maurya ${ }^{1}$ * \\ ${ }^{1}$ Regional Institute of Ophthalmology, Institute of Medical Sciences, Banaras Hindu University, Varanasi, Uttar Pradesh, India
}

\section{A R T I C L E I N F O}

Article history:

Received 25-09-2020

Accepted 26-09-2020

Available online 30-09-2020
(C) 2020 Published by Innovative Publication. This is an open access article under the CC BY-NC license (https://creativecommons.org/licenses/by-nc/4.0/)
The outbreak of 2019 novel corona virus disease (COVID-19) was started from Wuhan city of China on December 3, 2019 [World Health Organization] and in India COVID-19 was reported first time on January 30, 2020. Now this virus has spread across the world to become one of the most serious pandemic. Till September 27, 2020 this virus has caused nearly $32,429,965$ infections and 985,823 deaths all over world. ${ }^{1}$ In India, the total number of confirmed COVID-19 cases has exceeded 5,903,932 and 85,362 deaths have been reported as of September, 27,2020. [www.worldometer.info/corona virus last accessed on 2020, September 27].

COVID-19 has several connections with eye and Ophthalmologist. Dr Li Wenliang, Wuhan based Ophthalmologist first identified the epidemic and raised the initial alarms to the local authorities about this new virus and its dangers but he was falsely accused by the local security bureau forgiving wrong statements. Dr. Li Wenliang subsequently died of this disease, he thought, he was contaminated by an asymptomatic glaucoma patient. ${ }^{2,3}$

Yuen Ks et al. had reported about the clinical manifestations of this disease on ocular screening of SARs patients held in the year 2004, they had screened 45 such patients and identified common manifestations among patients treated with high dose of corticosteroids; the only positive finding was a raised IOP, which persisted even after discontinuation of the treatment. Since the COVID 19 virus is similar to the SARs virus, this prospect needs to be studied in future. ${ }^{4}$ On the basis of symptoms comparisons are being made with severe acute respiratory syndrome (SARS) and Middle East respiratory syndrome (MERS) as both of them are variants of corona virus. SARS and MERs have also been known to get transferred to surfaces and contamination can enter the human body by routes like nasal mucosa, ocular surfaces, oral mucosa subsequently. ${ }^{5}$

On the basis of experience with viral pandemics of SARs and MERs, we are capable of knowing about COVID-19 transmission and its direct and indirect human to human spread. Corona virus (SARS CoV) is found to be transmitted predominantly from one human to another via respiratory aerosols by direct contact or by fine droplets reaching the mucous membranes of the mouth nose or eyes. The body fluids and infectious droplets of a patient can find the eyes of a normal person as an entry point of the disease and vice versa from infected patients. Respiratory viruses are possible reason for ocular complications. ${ }^{6}$ It has been found that all kinds of body fluids may be responsible for transmission; Tears are a definite risk for SARS $\mathrm{CoV}$ transmission. Hence an exposure of naked eyes to 2019_nCoV can be a potential source of infection. Viral RNA has also been found in conjunctival scrapings, tear film, Pharyngeal swabs, sputum, nasal, Blood, faeces samples, Broncho-alveolar lavage fluid and fibro-bronchoscope brush biopsy from patients with severe illness or undergoing mechanical ventilation from infected patients, raising the possibility of transmission through the fecal/oral route. ${ }^{7}$ Infection to $\mathrm{Li}$ Wenliang from an asymptomatic glaucoma patient suggests that asymptomatic 
patients may be a significant source of spread. ${ }^{8}$ Although CoVs related virus mainly affect the respiratory system, manifestations range from mild to moderate common cold to severe forms like limb pain, fever, vomiting and other symptoms noted with MERS and SARS. Symptoms in the eyes were not commonly involved with MERS-CoV or SARs but it has been found by Polymerase chain reactions on tears and conjunctival scrapings that thevirus was present in such patients. Ocular signs are present in only a small percentage of patients. COVID patients present with pink eye, or conjunctivitis (especially mild follicular type), including bulbar conjunctival hyperemia, Epiphora or increased secretions may be present. This constitutes about $1 \%$ to $3 \%$ of people with coronavirus. It is pertinent to note that the human corona virus NL 63(HCoV-NL63) was first recognized in a baby who presented with Conjunctivitis and bronchiolitis. It was found in a study that out of 28 pediatric patients with infection by HCoV-NL63, as many as $17 \%$ had ocular signs. Symptoms can appear as early as two days from exposure to as late as 14 days.

At the moment, supportive therapeutic strategies are the only mainstay of treatment protocol, and prevention aimed at decreasing the transmission in the population is the best weapon. The chain of transmission can be broken through aggressive isolation measures; this has led to a progressive dropping of cases in the countries involved first. Topical anti histaminic eye drops, topical mild steroids and lubricants are safe and time tested treatments. In severe cases steroid drops like loteprednol $0.25 \%$ or Florometholone $0.1 \%$ may be used with caution. Repeated washings of eyes will decrease the load of pathogen and discharge, a secondary bacterial or fungal infection should be looked at, and corneal surface should be looked after for erosions. The use of protective goggles covering the whole eye, which cling to orbital margins, cannot be over emphasizedas a part of personal protective equipment (PPE) of care givers. ${ }^{9}$ A simple Fluorescien stain will identify a viral pattern of corneal pathology, Topical Acyclovir 3\% has been successfully used in SARs hence may be used here too.

Hydroxychloroquine (HCQ), an antimalarial has been proposed as a possible treatment for coronavirus disease2019 (COVID-19). India has approved the use of HCQ for prophylaxis of asymptomatic health workers treating suspected or confirmed COVID-19 cases, and asymptomatic household contacts of confirmed patients. The U.S. Food and Drug Administration has issued Emergency Use Authorization for the use of HCQ to treat COVID19 in adolescents and adults. The possibility of retinal toxicity in the form of bull's eye maculopathy can not be neglected in such cases hence regular fundus examination by ophthalmologist is necessary.

The respiratory tract is probably not the only transmission route for $2019 \mathrm{nCoV}$, polymerase chain reaction on tears and conjunctiva from patients with SARS-CoV infection have shown presence of the virus, reports suggest that about 1,700 healthcare professionals have been infected through this route resulting in 6 deaths including one ophthalmologist. Despite being fully covered by aprons and gown as protective suit and masked respirator, health worker were still contaminated by the virus with the first warning sign being unilateral red eye or conjunctivitis, followed by development of fever a few hours later. Since the appearance of this report, healthcare professionals have been advised to use eye protection when they are in close contact with patients. There is a controversy over what constitutes an appropriate PPE for an Ophthalmologist to conduct ophthalmic examination, in context with glasses and masks. There have been instances of deaths of ophthalmologist and otolaryngologist in China and Italy, environmental virus contamination has increased awareness to favor mouth, eye and nose protection. It is hence been made mandatory by the Centre for Disease Control and Prevention (Govt of India), for all health workers and patients to wear surgical masks to reduce asymptomatic transmission. In hotspots, hospitals require all caregivers and frontline workers to wear N-95 masks. However, because red eye or conjunctivitis is an overall common condition, and such patients more often present to eye clinics or emergency departments, it is possible that ophthalmologists are the first person to examine the patients possibly infected with COVID-19. There is always a chance of a COVID 19 infected patient having conjunctivitis to have a viral presence in his tear secretions, so the area needs to be sanitized, once the patient leaves. While performing a slit lamp biomicroscopy, slit-lamp breaths shields are have been used by care givers. Careful "hand washes" after every patient is a must for all ophthalmologists. They should avoid touching nose mouth or face or eyes before a hand wash.Usage of tissue wipes should be promoted if there is an urge to itch over the face area. Lubricant eye drops should be used more frequently as dry eyes can lead to more rubbing and friction.Despite all efforts, if there is an exposure to the eyes of the care giver, eyes may be washed by clean running water, and soaked dry.

\section{Conflict of Interest}

None.

\section{References}

1. World Health Organization. Pneumonia of unknown cause-China, 2020. Available from: www.who.int/Covid-19/information.

2. Huang C, Wang Y, Li X, Ren L, Zhao J, Hu Y. Clinical features of patients infected with 2019 novel coronavirus in Wuhan, China. Lancet. 2020;01:10.1016/S0140-6736(20)30183-5.

3. WHO. Laboratory testing for 2019 novel coronavirus $(2019-n C o V)$ in suspected human cases interim guidance; 2020.

4. Yuen KS, Ye ZW, Fung SY, Chan CP, Jin DY. SARS-CoV-2 and COVID-19: The most important research questions. Cell Biosci. 2020;10:40.

5. Otter JA, Donskey C, Yezli S, Douthwaite S, Goldenberg SD, Weber DJ. Transmission of SARS and MERS coronaviruses and influenza virus in 
healthcare settings: the possible role of dry surface contamination. $J$ Hosp Infect. 2016;92(3):235-50.

6. Liu J, Liao X, Qian S, Yuan J, Wang F, Liu Y, et al. Community transmission of severe acute respiratory syndrome coronavirus 2 . Emerg Infect Dis. 2020;26(6):1320-3.

7. Li Q, Guan X, Wu P, Wang X, Zhou L, Tong Y, et al. Early transmission dynamics in Wuhan, China, of novel coronavirus-infected pneumonia. N Engl J Med. 2020;382(13):1199-1207.

8. Peterson E, Hui D, Hamer DH. Li Wenliang, a face to frontline healthcare worker. The first doctor to notify the emergence of the SARsCoV-2,(COVID 19) outbreak. Int J Infect Dis. 2020;93:205-7.

9. Hu K, Patel J, Patel BC. Ophthalmic Manifestations of Coronavirus(COVID19). Stat Pearls Publishing; 2020.

\section{Author biography}

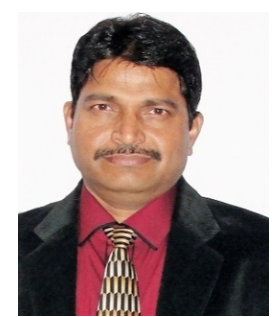

Rajendra P Maurya (MS, Ph.D) Editor in Chief IJCEO, Senior Assistant Professor \& I/c Orbit, Ocular Oncology and Oculoplasty Unit Regional Institute of Ophthalmology, Institute of Medical Sciences,

Banaras Hindu University, Varanasi, (UP), India

E-mail: editorijceo@gmail.com,

mauryarpbhu@yahoo.com

Cite this article: Maurya RP. COVID-19 and Ophthalmologists. Indian J Clin Exp Ophthalmol 2020;6(3):312-314. 